\title{
Effects of trans-10, cis-12 conjugated linoleic acid on the expression of uncoupling proteins in hamsters fed an atherogenic diet
}

\author{
Joan Ribot ${ }^{1}$, Maria P. Portillo ${ }^{2}$, Catalina Picó $^{1}$, M. Teresa Macarulla ${ }^{2}$ and Andreu Palou ${ }^{1}$ \\ ${ }^{1}$ Bioquímica, Biología Molecular, Nutrición y Biotecnología (Nutrigenómica), Universitat de les Illes Balears (UIB), Cra. \\ Valldemossa, km 7.5, 07122 Palma de Mallorca, Spain \\ ${ }^{2}$ Department of Nutrition and Food Science, University of País Vasco, Paseo de la Universidad 7, 01006 Vitoria, Spain
}

(Received 6 September 2006 - Revised 29 November 2006 - Accepted 3 January 2007)

\begin{abstract}
It is known that conjugated linoleic acid (CLA) feeding decreases body adiposity but the mechanisms involved are not clear. The aim of this study was to analyse whether alterations in uncoupling protein (UCP) expression in white and brown adipose tissues (WAT and BAT, respectively) and in skeletal muscle may be responsible for the effect of trans-10, cis-12 CLA on the size of body fat depots in hamsters. Animals were divided into three groups and fed an atherogenic diet with different amounts of trans-10, cis-12 CLA ( 0 control, $0 \cdot 5$, or $1 \mathrm{~g} / 100 \mathrm{~g}$ diet) for $6 \mathrm{weeks}$. CLA feeding reduced adipose depot weights, but had no effect on body weight. Leptin mRNA expression decreased in both subcutaneous and perirenal WAT depots, in accordance with lower adiposity, whereas resistin mRNA expression was not changed. Animals fed CLA had lower UCP1 mRNA levels in BAT (both doses of CLA) and in perirenal WAT (the low dose), and lower UCP3 mRNA levels in subcutaneous WAT (the high dose). UCP2 mRNA expression in WAT was not significantly affected by CLA feeding. Animals fed the high dose of CLA showed increased UCP3 and carnitine palmitoyl transferase-I (CPT-I) mRNA expression levels in skeletal muscle. In summary, induction of UCP1 or UCP2 in WAT and BAT is not likely to be responsible for the fat-reduction action of CLA, but the increased expression of UCP3 in skeletal muscle, together with a higher expression of CPT-I, may explain the previously reported effects of dietary CLA in lowering adiposity and increasing fatty acid oxidation by skeletal muscle.
\end{abstract}

Conjugated linoleic acid: Uncoupling proteins: Atherogenic diet: Hamster

CLA (conjugated linoleic acid) is the acronym describing a group of octadecadienoic acids (18:2) which are isomers of the essential fatty acid, linoleic acid (C18:2 n-6), whose double bonds are not separated by a methylene group but are conjugated. The CLA chemically produced for commercialisation and used in dietetic complements or foods is usually a relatively rich (about 55 and 90\%) CLA mixture containing about equal proportions of two isomers, trans-10, cis-12-CLA and cis-9, trans-11 CLA (Gaullier et al. 2002) with a minor contribution from other isomers.

Interest in CLA arose, initially, in its anticarcinogenic action (Pariza et al. 1979) but there is an increasing amount of specific scientific literature on the biological effects and properties of CLA (for current citations of the published scientific literature on CLA, see http://www.wisc.edu/fri/clarefs. htm). In particular, CLA has been shown to decrease body fat in various animal models including mice, rats, hamsters and pigs, as well as in man (Park et al. 1997; Azain et al. 2000; Gavino et al. 2000; Kritchevsky et al. 2000; Tsuboyama-Kasaoka et al. 2000; Cherian et al. 2002; Navarro et al. 2003; Ostrowska et al. 2003; Pariza, 2004; Terpstra, 2004). Although in most of the published studies concerning
CLA, mixtures with different isomer proportions have been used (Navarro et al. 2006), there is strong evidence indicating that the biologically active isomer showing anti-obesity effects is trans-10, cis-12 (Evans et al. 2002a; Martin \& Valeille, 2002).

Several mechanisms of action have been proposed to explain the fat-lowering effect of CLA: decreased energy intake (Kamphuis et al. 2003); increased energy expenditure (West et al. 2000); increased lipolysis and fatty acid oxidation (Evans et al. 2002b; Macarulla et al. 2005); decreased TAG synthesis and fatty acid uptake (Evans et al. 2000); decreased pre-adipocyte differentiation (Brodie et al. 1999) and increased apoptosis (Tsuboyama-Kasaoka et al. 2000), but evidence supporting these mechanisms is not equally strong. Concerning energy expenditure, several works in the literature have been devoted to analyse the effects of CLA on the expression of uncoupling proteins (UCP) which are transmembrane proteins found in the inner mitochondrial membrane that dissipate energy as heat and consequently increase energy expenditure. However, the results obtained are still scarce and not very consistent, and show species-specific differences (Tsuboyama-Kasaoka et al. 2000; West et al. 2000; Ryder

\footnotetext{
Abbreviations: BAT, brown adipose tissue; CLA, conjugated linoleic acid; CPT-I, carnitine palmitoyl transferase I; UCP, uncoupling protein; WAT, white adipose tissue.

* Corresponding author: Dr M. P. Portillo, fax: +34 945013014, email mariapuy.portillo@ehu.es
} 
et al. 2001; Ealey et al. 2002; Roche et al. 2002; Rodriguez et al. 2002; Takahashi et al. 2002; Choi et al. 2004).

We have previously reported that the addition of trans-10, cis-12 CLA (supplemented as $0.5 \mathrm{~g} / 100 \mathrm{~g}$ diet) for 6 weeks to an atherogenic diet (high-fat, high-sucrose) can prevent body fat accumulation induced by this diet in hamsters (Navarro et al. 2003) by the inhibition of adipogenesis (Simon et al. 2005, 2006) and the increase in liver and muscle fatty acid oxidation (Macarulla et al. 2005; Zabala et al. 2006). In order to attain more insight into the effect of CLA on energy metabolism, we analysed the effect of two different doses of trans-10, cis-12 CLA (0.5 and $1 \mathrm{~g} / 100 \mathrm{~g}$ diet) on the expression of UCP1, 2 and 3 in brown and white adipose tissues (BAT and WAT, respectively) and in skeletal muscle, which play a crucial role in regulating WAT mass, in hamsters fed an atherogenic diet. Because the influence of trans-10, cis-12 CLA on glucose homeostasis remains a matter of concern, we also analysed its effects on leptin and resistin expression in adipose tissues and GLUT4 and carnitine palmitoyl transferase-I (CPT-I) expression in skeletal muscle.

\section{Materials and methods}

\section{Animals, diets and experimental design}

The experiment was conducted with thirty 9-week-old, male Syrian Golden hamsters purchased from Harlan Iberica (Barcelona, Spain) and took place in accordance with the institution's guide for the care and use of laboratory animals. The hamsters were individually housed in polycarbonate metabolic cages (Techniplast Gazzada, Guguggiate, Italy) and placed in an airconditioned room $\left(22 \pm 2^{\circ} \mathrm{C}\right)$ with a $12 \mathrm{~h}$ light-dark cycle. After a $6 \mathrm{~d}$ adaptation period, hamsters were randomly divided into three dietary groups of ten animals each for feeding varied doses of trans-10, cis-12 CLA as NEFA (0 (control), 0.5 and $1.0 \mathrm{~g} / 100 \mathrm{~g}$ diet) in a semi-purified atherogenic diet consisting of $(\mathrm{g} / \mathrm{kg}): 200$ casein (Sigma, St. Louis, MO, USA), 4 L-methionine (Sigma), 200 wheat starch (Vencasser, Bilbao, Spain), 405 sucrose (local market), 100 palm oil (Agra-Unilever, Leioa, Spain), 30 cellulose (Vencasser), 4 choline-HCl (Sigma) and 1 cholesterol (Sigma). Trans-10, cis-12 CLA was supplied by Natural Lipids Ltd. (Hovdebygda, Norway). Vitamin (11 g/ $\mathrm{kg})$ and mineral $(40 \mathrm{~g} / \mathrm{kg})$ mixes were formulated according to AIN-93 guidelines (Reeves et al. 1993) and supplied by ICN Pharmaceuticals (Costa Mesa, CA, USA). The experimental diets were freshly prepared once a week, gassed with $\mathrm{N}_{2}$, and stored at $0^{\circ} \mathrm{C}$ to $4^{\circ} \mathrm{C}$ to avoid rancidity.

At the end of the experimental period ( 6 weeks) animals were sacrificed under anaesthesia (diethyl ether) and blood was collected by cardiac puncture. Perirenal and subcutaneous WAT depots, interscapular BAT and gastrocnemius muscles were dissected, weighed, sliced and immediately frozen. Serum was obtained from blood samples after centrifugation $(1000 \mathrm{~g}$ for $10 \mathrm{~min}$ at $4^{\circ} \mathrm{C}$ ). Samples were stored at $-80^{\circ} \mathrm{C}$ until analysis.

\section{Serum leptin concentration}

Serum leptin concentration was measured with a mouse leptin enzyme-linked immunosorbent assay (ELISA) kit (R\&D Systems, Minneapolis, MIN, USA).

\section{Total RNA preparations}

Adipose tissue and muscle samples were homogenised in Tripure reagent (Roche, Barcelona, Spain) with a Teflon/glass homogeniser (10 to 15 strokes) and total RNA was isolated according to the instructions of the manufacturer. The yield and purity of total RNA was measured spectrophotometrically. The ratio of absorption at 260 and $280 \mathrm{~nm}$ (A260/A280) was between 1.5 and 1.8 for all preparations. Integrity of the RNA extracted was further verified by ethidium bromide staining, after electrophoresis in $1 \%$ agarose gels.

\section{Northern blot analysis}

Total RNA ( $25 \mu \mathrm{g}$ ), denatured with formamide/formaldehyde, was fractionated by agarose gel electrophoresis as previously described (Oliver et al. 2000). The RNA was then transferred onto a Hybond Nylon membrane in $20 \times \mathrm{SSC}$ (saline sodium citrate buffer: $1 \times \mathrm{SSC}$ in $150 \mathrm{~mm} \mathrm{NaCl}, 15 \mathrm{~mm}$ sodium citrate, $\mathrm{pH} 7 \cdot 0$ ) by capillary blotting for $16 \mathrm{~h}$, and fixed with UV light (Oliver et al. 2000).

The mRNA for UCP1, UCP2, UCP3 leptin and resistin and the 18S rRNA (used as a control to check the loading and transfer of RNA during blotting) were detected by a chemiluminescence-based procedure, using specific antisense oligonucleotide probes which were synthesised commercially (TIB MOLBIOL, Berlin, Germany), labelled at both ends with a single digoxigenin ligand. The probes were: for UCP1, $5^{\prime}$ GAAGACCACTGTACAGTTTCGGCAACCCTTCTG-3'; for UCP2, 5'-GGCAGAGTTCATGTATCTCGTCTTGACCAC3'; for UCP3, 5'-GACTCCTTCTTCCCTGGCGATGGTTCTGTAGG-3'; for leptin, 5' - GGTCTGAGGCAGGGAGCAGCTCTTGGAGAAGGC-3'; for resistin, 5'-CCCACGAGCCACAGGCAGAGCCACAGGAGCAGC-3' and for 18S, 5'-CGCCTGCTGCCTTCCTTGGATGTGGTAGCCG-3'. Prehybridisation was at $42^{\circ} \mathrm{C}$ for $15 \mathrm{~min}$ in DIG-Easy Hyb (Roche, Barcelona, Spain). Hybridisation was at $42^{\circ} \mathrm{C}$ overnight in DIGEasy Hyb containing the oligonucleotide probe $(34 \mathrm{ng} / \mathrm{ml}$ for the specific mRNA and $70 \mathrm{pg} / \mathrm{ml}$ for $18 \mathrm{~S}$ rRNA). Then, hybridised membranes were washed twice for $15 \mathrm{~min}$ at room temperature with $2 \times \mathrm{SSC}-0.1 \%$ SDS (sodium dodecyl sulphate) followed by two $15 \mathrm{~min}$ washes at $48^{\circ} \mathrm{C}$ with $0.1 \times \mathrm{SSC}-$ $0.1 \%$ SDS. After $1 \mathrm{~h}$ blocking at room temperature with Blocking reagent (Roche), the membranes were incubated first with antidigoxigenin-alkaline phosphatase conjugate (Roche) and then with the chemiluminescent substrate CDPStar (Roche). Finally, membranes were exposed to Hyperfilm ECL (Amersham Biosciences, Barcelona, Spain). Bands in films were analysed by scanner photodensitometry and quantified using the KODAK 1D Image Analysis Software 3.5 (Kodak, Mering, Germany). Blots were stripped and reprobed sequentially for the other specific mRNA. Finally, blots were stripped and reprobed for $18 \mathrm{~S}$ rRNA as previously described (Oliver et al. 2000). Levels of mRNA were expressed as the ratio of their specific signal intensity relative to that for $18 \mathrm{~S}$ rRNA.

\section{Reverse transcriptase-polymerase chain reaction analysis}

Levels of CPT-I, GLUT4, mRNA and 18S rRNA (used as a control) were semi-quantified by a RT-PCR assay (Ribot et al. 2001). In brief, $1 \mu \mathrm{g}$ total RNA was denatured at $65^{\circ} \mathrm{C}$ for 
$10 \mathrm{~min}$ and reverse-transcribed in the presence of $50 \mathrm{pmol}$ random primers, using MuLV reverse transcriptase (PerkinElmer, Wellesley, MA, USA) at $42^{\circ} \mathrm{C}$ for $40 \mathrm{~min}$ in a PerkinElmer 9700 Thermal Cycler. After the reaction, the RT medium (4\%) was added to a PCR mix containing Taq DNA polymerase (Promega, Lyon, France) and 20 pmol (for CPT-I and GLUT4 mRNA) or 1 pmol (for $18 \mathrm{~S}$ rRNA) primers. Specific sense and antisense primers used were designed with specific primer analysis software Primer3 (Whitehead Institute for Biomedical Research, Cambridge, MA, USA) and were: for CPT-I, sense primer $5^{\prime}$-GGCTATCTGTGTTCGCCTTC-3' and antisense primer $5^{\prime}$-TGGGGGCAGTGTTGTTCT-3'; for GLUT4, sense primer 5'-GGCATGGGTTTCCAGTATGT-3' and antisense primer $5^{\prime}$-GCCCCTCAGTCATTCTCATC- $3^{\prime}$ and for $18 \mathrm{~S}$ rRNA, sense primer $5^{\prime}$-GGACCAGAGCGAAAGCATTTGCC- $3^{\prime}$ and antisense primer $5^{\prime}$-TCAATCTCGGGTGGCTGAACGC- $3^{\prime}$. The specificity of the sequences and primer binding sites were analysed by the ENTREZ and BLAST database utilities (National Center for Biotechnology Information, Bethesda, MD, USA). The reaction mixture was first heated to $95^{\circ} \mathrm{C}$ for $2 \mathrm{~min}$ to denature the cDNA. This was followed by cycles of denaturation (twenty four for CPT-I, twenty six for GLUT4 and fourteen for $18 \mathrm{~S} \mathrm{rRNA}$ ) at $95^{\circ} \mathrm{C}$ for $15 \mathrm{~s}$, annealing at $60^{\circ} \mathrm{C}$ (for CPT-I and $18 \mathrm{~S}$ rRNA) or $61^{\circ} \mathrm{C}$ (for GLUT4) for $15 \mathrm{~s}$ and extension at $72^{\circ} \mathrm{C}$ for $30 \mathrm{~s}$, with an additional extension at $72^{\circ} \mathrm{C}$ for $7 \mathrm{~min}$ after the last cycle. The PCR products were separated in $3 \%$ agarose gel (MS-8; Pronadisa, Madrid, Spain) in $0.5 \times$ Tris-borate EDTA buffer, stained with ethidium bromide and visualised using an image recording system (GeneSnap/Chemigenius; Syngene, Cambridge, UK). The densities of the target bands were then quantified using an image processing and analysing program (GeneTools; Syngene). Levels of mRNA were expressed as the ratio of signal intensity for specific mRNA relative to that for $18 \mathrm{~S}$ rRNA. Linearity of the RT -PCR was tested using different amounts of total RNA (results not shown).

\section{Statistical analysis}

Data are expressed as means with their standard errors. Statistical significance was assessed by one-way ANOVA followed by the least significant difference post hoc comparison or by Student's $t$ test. The minimum significance level was set at $P<0.05$. The analyses were performed with SPSS for Windows (SPSS, Chicago, IL, USA).

\section{Results}

Trans-10, cis-12 CLA feeding, both the low and the high dose, resulted in significantly lower weight of the subcutaneous and perirenal WAT depots, without modifying interscapular BAT weight (Table 1). These effects on adiposity were not dependent on the dose. In addition, animals fed $1 \%$ CLA showed significantly greater gastrocnemius muscles than control animals and those fed $0.5 \%$ CLA. As previously reported (Zabala et al. 2006), CLA treatment did not affect final body weight of animals compared with their controls, but animals fed $1 \%$ CLA showed significantly greater final body weight than those fed $0.5 \%$ CLA $(P<0 \cdot 05)$. No significant differences in food intake were found between the three experimental groups.

Leptin mRNA expression levels varied depending on the adipose tissue depot $(P<0 \cdot 05)$. Representative northern blots for leptin expression in adipose tissues are shown comparing the patterns of control hamsters (Fig. 1). As a general feature, leptin expression was higher in subcutaneous WAT than in perirenal WAT and interscapular BAT. A similar pattern for the resistin mRNA expression was observed in the adipose depots analysed, but the differences did not attain statistical significance.

In accordance with lower body fat mass, animals fed CLA (both the low and the high dose) displayed significantly lower leptin mRNA expression levels in both subcutaneous and perirenal WAT depots, and again, no dose-dependent effect was observed (Table 2). A trend to lower circulating leptin was also observed as an effect of CLA (722 (SEM 182) pg/ml in controls, 292 (SEM 91) pg/ml in 0.5\% CLA-treated animals, and 373 (SEM 59) $\mathrm{pg} / \mathrm{ml}$ in 1\% CLA-treated animals), although differences were not statistically significant $(P=0 \cdot 057)$. Resistin mRNA expression levels in both WAT depots studied tended to decrease by CLA feeding (Table 2) but did not attain statistical significance. No changes were

Table 1. Effects of trans-10, cis-12 conjugated linoleic acid (CLA) supplementation on body weight, food intake, and the weights of subcutaneous and perirenal white adipose tissues and gastrocnemious muscle ${ }^{\star} \dagger$

(Values are means with their standard errors for ten animals per group)

\begin{tabular}{|c|c|c|c|c|c|c|c|}
\hline & \multicolumn{2}{|c|}{ Control } & \multicolumn{2}{|c|}{$0.5 \%$ CLA } & \multicolumn{2}{|c|}{$1 \%$ CLA } & \multirow[b]{2}{*}{ ANOVA } \\
\hline & Mean & SEM & Mean & SEM & Mean & SEM & \\
\hline Body weight (g) & 121 & $3^{a b}$ & 119 & $1^{\mathrm{b}}$ & 124 & $2^{a}$ & $P<0.05$ \\
\hline Food intake $(\mathrm{g} / \mathrm{d})$ & 6.03 & 0.14 & 5.66 & 0.08 & 5.73 & $0 \cdot 12$ & \\
\hline \multicolumn{8}{|l|}{ Adipose tissues (g) } \\
\hline SWAT & $3 \cdot 78$ & $0.25^{a}$ & 2.67 & $0 \cdot 14^{b}$ & 2.95 & $0 \cdot 14^{b}$ & $P<0.001$ \\
\hline pWAT & 1.68 & $0 \cdot 10^{\mathrm{a}}$ & $1 \cdot 19$ & $0.09^{b}$ & 1.42 & $0.08^{b}$ & $P<0.05$ \\
\hline BAT & 0.34 & 0.01 & 0.31 & 0.01 & 0.29 & 0.02 & \\
\hline Gastrocnemious muscle (mg) & 598 & $18^{a}$ & 599 & $19^{a}$ & 654 & $13^{b}$ & $P<0.05$ \\
\hline
\end{tabular}

sWAT, subcutaneous white adipose tissue; pWAT, perirenal white adipose tissue; BAT, interscapular brown adipose tissue.

* 9 -week-old, male Syrian Golden hamsters were fed with a semi-purified atherogenic diet supplemented with different doses of trans-10, cis-12 CLA as NEFA (0 (control), 0.5 and $1.0 \mathrm{~g} / 100 \mathrm{~g}$ diet) for 6 weeks.

†Data on body weight, food intake and the weight of gastrocnemius muscle have been previously published (Zabala et al. 2006).

a,b Values in the same row not sharing a common letter were statistically different. Significant differences were tested by one way ANOVA and least significant difference post hoc comparisons $(P<0.05)$. 


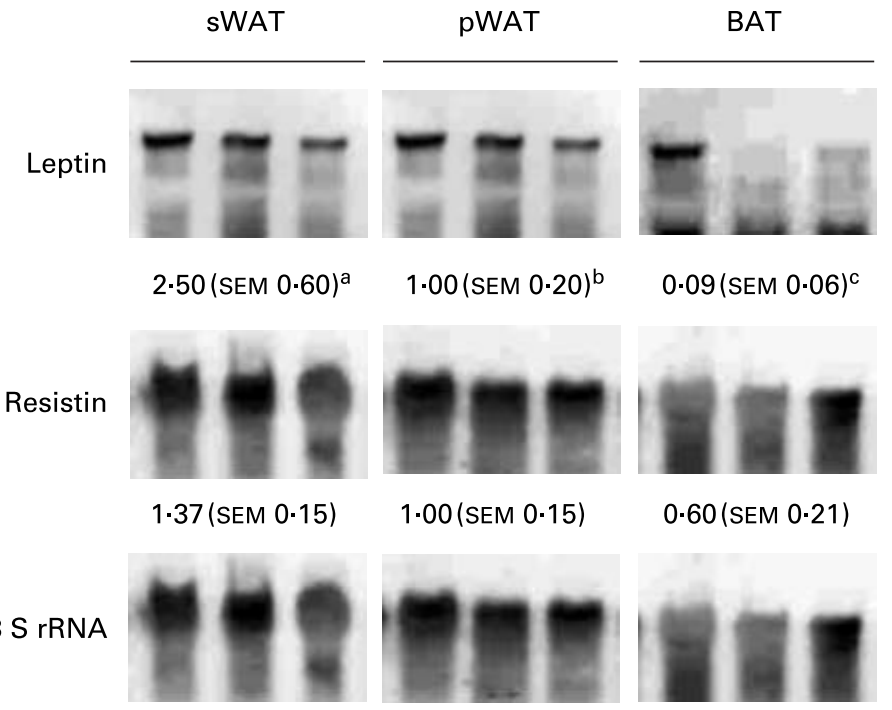

Fig. 1. Representative northern blots comparing the relative mRNA levels of leptin and resistin between subcutaneous white adipose tissue (sWAT), perirenal white adipose tissue (pWAT) and interscapular brown adipose tissue (BAT) in control male hamsters fed an atherogenic diet. Total RNA (25 $\mu \mathrm{g}$ ) was used for specific determination of the mRNA, using 18 S rRNA as a control for quantity of RNA. Data represent means with their standard errors for 3-5 animals per group and are expressed relative to the mean value of the PWAT, which was set to 1. Significant differences were tested by one-way ANOVA and least significant difference post hoc comparisons. ${ }^{\mathrm{a}, \mathrm{b}, \mathrm{c}}$ Values in the same row not sharing a common letter were statistically different $(P<0.05)$.

found concerning leptin and resistin expression in BAT as an effect of CLA feeding (data not shown), although it should be pointed out that in this tissue the expression levels of these genes were very low compared with WAT (see Fig. 1, corresponding to control animals).

UCP1 mRNA expression was measured in BAT and WAT depots and significant expression was found in BAT and also in the perirenal WAT (see Fig. 2, corresponding to control animals). In both depots, CLA feeding resulted in lower UCP1 mRNA levels, the decrease being significant $(P<0.05)$ with both doses in BAT and with the lower dose in perirenal WAT (Table 3). UCP2 mRNA expression in both WAT depots studied was not significantly affected by CLA feeding, although a tendency to lower levels was observed in both depots (Table 3). No significant UCP2 mRNA expression was detected in BAT (see Fig. 2, corresponding to control animals).
The effect of CLA on UCP3 expression was tissue-specific. Animals fed the high dose of CLA showed decreased UCP3 mRNA expression levels in the subcutaneous WAT depot (Table 3), but increased expression in the skeletal muscle $(P<0.05$; Fig. 3). No statistically significant effect was observed in the perirenal WAT depot or BAT. The increased UCP3 mRNA levels in the skeletal muscle with the high dose of CLA were also accompanied by increased CPT-I mRNA expression and a tendency to lower GLUT4 mRNA expression in this tissue (Fig. 3). No significant changes were observed with the low dose of CLA on UCP3, CPT-I and GLUT4 expression in gastrocnemious muscle (data not shown).

\section{Discussion}

It is increasingly known that CLA isomers have different effects which may even be opposing (Evans et al. 2002a,

Table 2. Effects of trans-10, cis-12 conjugated linoleic acid (CLA) supplementation on the relative leptin and resistin mRNA levels in subcutaneous and perirenal white adipose tissues*

(Values are means with their standard errors for six to nine animals per group and are expressed relative to the mean value of the control group, which was set to 100).

\begin{tabular}{|c|c|c|c|c|c|c|c|}
\hline & \multicolumn{2}{|c|}{ Control } & \multicolumn{2}{|c|}{$0.5 \%$ CLA } & \multicolumn{2}{|c|}{$1 \%$ CLA } & \multirow[b]{2}{*}{ ANOVA } \\
\hline & Mean & SEM & Mean & SEM & Mean & SEM & \\
\hline \multicolumn{8}{|l|}{ sWAT } \\
\hline mRNA Leptin & 100 & $7 \cdot 3^{\mathrm{a}}$ & 54.6 & $4 \cdot 4^{\mathrm{b}}$ & $66 \cdot 8$ & $6 \cdot 4^{\mathrm{b}}$ & $P<0.001$ \\
\hline mRNA Resistin & 100 & 9.8 & 74.4 & $6 \cdot 0$ & $86 \cdot 2$ & $6 \cdot 1$ & \\
\hline \multicolumn{8}{|l|}{ pWAT } \\
\hline mRNA Leptin & 100 & $12^{\mathrm{a}}$ & $67 \cdot 8$ & $3 \cdot 4^{\mathrm{b}}$ & $69 \cdot 3$ & $10^{\mathrm{b}}$ & $P<0.05$ \\
\hline mRNA Resistin & 100 & 15 & $72 \cdot 6$ & 8.5 & $86 \cdot 3$ & 16 & \\
\hline
\end{tabular}

sWAT, subcutaneous white adipose tissue; pWAT, perirenal white adipose tissue.

* 9 -week-old, male Syrian Golden hamsters were fed with a semi-purified atherogenic diet supplemented with different doses of trans-10, cis-12 CLA as NEFA (0 (control), 0.5 and $1.0 \mathrm{~g} / 100 \mathrm{~g}$ diet) for 6 weeks. mRNA levels were analysed by northern blot. Total RNA $(25 \mu \mathrm{g})$ was used for specific determination of the mRNA, using $18 \mathrm{~S}$ rRNA as a control for quantity of RNA.

a,b Values in the same row not sharing a common letter were statistically different. Significant differences were tested by one way ANOVA and least significant difference post hoc comparisons $(P<0 \cdot 05)$. 


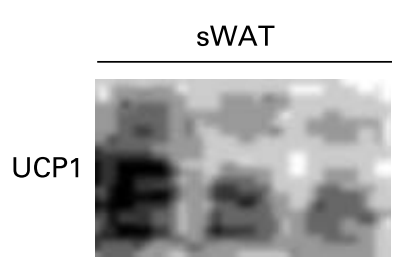

ND

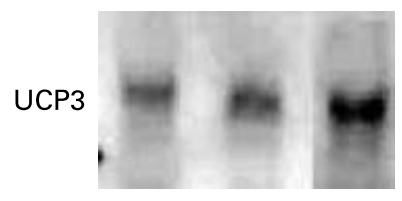

0.93 (SEM 0.15)

UCP2

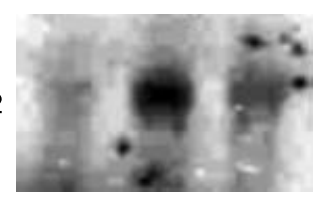

1.66 (SEM 0.84)

18 S rRNA

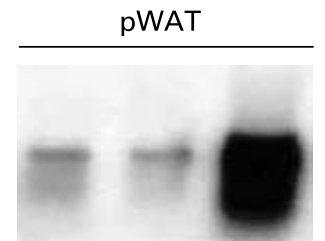

$1.00(\text { SEM } 0.31)^{\mathrm{a}}$

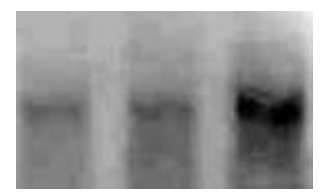

1.00 (SEM 0.22 )

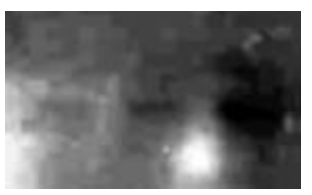

1.00 (SEM 0.31 )

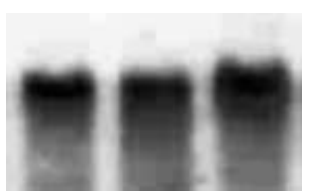

BAT

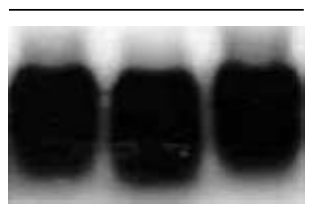

$2.53(\text { SEM } 0.12)^{b}$

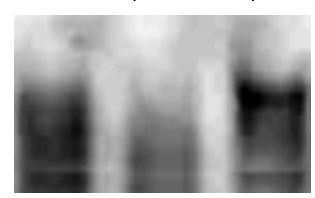

1.01 (SEM 0.50)

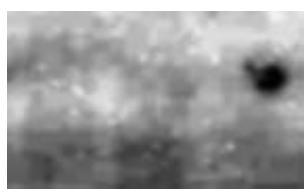

ND

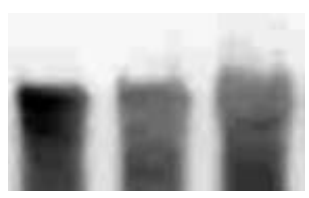

Fig. 2. Representative northern blots comparing the relative mRNA levels of uncoupling proteins (UCP) 1, 2 and 3 between subcutaneous white adipose tissue (sWAT), perirenal white adipose tissue (pWAT) and interscapular brown adipose tissue (BAT) in control male hamsters fed an atherogenic diet. Total RNA (25 $\mu$ ) was used for specific determination of the mRNA, using $18 \mathrm{~S}$ rRNA as a control for quantity of RNA. Data represent means with their standard errors for 3-5 animals per group and are expressed relative to the mean value of the pWAT, which was set to 1. Significant differences were tested by one-way ANOVA and least significant difference post hoc comparisons. ${ }^{\mathrm{a}, \mathrm{b}}$ Values in the same row not sharing a common letter were statistically different $(P<0.05)$. ND, not detected.

Table 3. Effects of trans-10, cis-12 conjugated linoleic acid (CLA) supplementation on the relative uncoupling proteins (UCP) 1,2 and 3 mRNA levels in adipose tissues*

(Values are means with their standard errors for six to nine animals per group and are expressed relative to the mean value of the control group, which was set to 100)

\begin{tabular}{|c|c|c|c|c|c|c|c|}
\hline & \multicolumn{2}{|c|}{ Control } & \multicolumn{2}{|c|}{$0.5 \%$ CLA } & \multicolumn{2}{|c|}{$1 \%$ CLA } & \multirow[b]{2}{*}{ ANOVA } \\
\hline & Mean & SEM & Mean & SEM & Mean & SEM & \\
\hline \multicolumn{8}{|l|}{ sWAT } \\
\hline mRNA UCP1 & \multicolumn{2}{|c|}{ ND } & \multicolumn{2}{|c|}{ ND } & \multicolumn{2}{|c|}{ ND } & \\
\hline mRNA UCP2 & 100 & 14 & $85 \cdot 0$ & 11 & $65 \cdot 0$ & 10 & \\
\hline mRNA UCP3 & 100 & $8.9^{a}$ & 93.1 & $3.7^{\mathrm{ab}}$ & $69 \cdot 2$ & $11^{\mathrm{b}}$ & $P<0.05$ \\
\hline \multicolumn{8}{|l|}{ pWAT } \\
\hline mRNA UCP1 & 100 & $26^{a}$ & 31.4 & $15^{\mathrm{b}}$ & $51 \cdot 8$ & $16^{\mathrm{ab}}$ & $P<0.05$ \\
\hline mRNA UCP2 & 100 & 31 & $45 \cdot 5$ & 14 & $40 \cdot 3$ & 11 & \\
\hline mRNA UCP3 & 100 & 22 & 104 & $3 \cdot 1$ & 113 & 9.4 & \\
\hline \multicolumn{8}{|l|}{ BAT } \\
\hline mRNA UCP1 & 100 & $20^{\mathrm{a}}$ & $55 \cdot 3$ & $7 \cdot 5^{\mathrm{b}}$ & $55 \cdot 6$ & $10^{\mathrm{b}}$ & $P<0.05$ \\
\hline mRNA UCP2 & \multicolumn{2}{|c|}{ ND } & \multicolumn{2}{|c|}{ ND } & \multicolumn{2}{|c|}{ ND } & \\
\hline mRNA UCP3 & 100 & 35 & 146 & 23 & $76 \cdot 7$ & 17 & \\
\hline
\end{tabular}

sWAT, subcutaneous white adipose tissue; pWAT, perirenal white adipose tissue; BAT, interscapular brown adipose tissue; ND, not detected by northern blot.

* 9 -week-old, male Syrian Golden hamsters were fed with a semi-purified atherogenic diet supplemented with different doses of trans-10, cis-12 CLA as NEFA (0 (control), 0.5 and $1.0 \mathrm{~g} / 100 \mathrm{~g}$ diet) for 6 weeks. mRNA levels were analysed by northern blot. Total RNA $(25 \mu \mathrm{g})$ was used for specific determination of the mRNA, using $18 \mathrm{~S}$ rRNA as a control for quantity of RNA.

a,b Values in the same row not sharing a common letter were statistically different. Significant differences were tested by one way ANOVA and least significant difference post hoc comparisons $(P<0.05)$. 


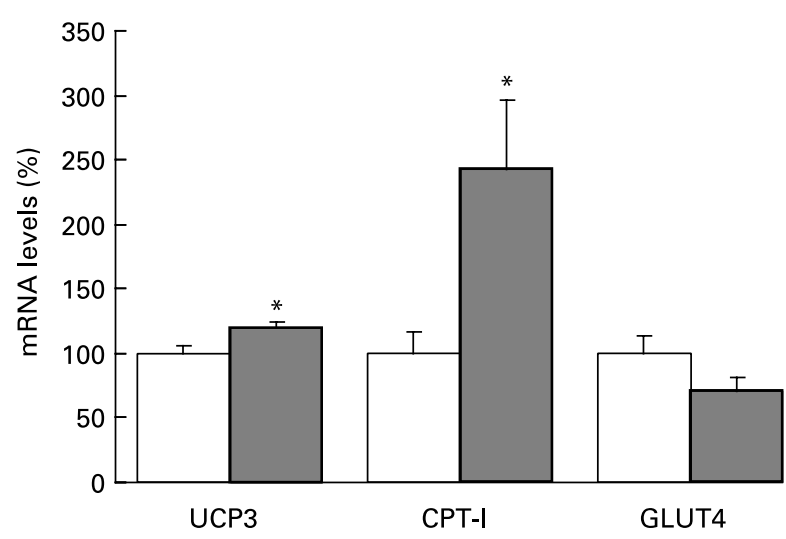

Fig. 3. Effects of trans-10, cis-12 conjugated linoleic acid (CLA) supplementation on the relative uncoupling protein 3 (UCP3), carnitine palmitoyl transferase I (CPT-I) and GLUT4 in gastrocnemious muscle. Male Syrian Golden hamsters (9-weeks-old) were fed with a semi-purified atherogenic diet supplemented with $1.0 \mathrm{~g}$ trans -10 , cis-12 CLA as NEFA $100 \mathrm{~g}$ diet ( $\square$ ), or without supplementation (control; $\square$ ), for 6 weeks. UCP3 mRNA levels were analysed by Northern blot, using $25 \mu \mathrm{g}$ total RNA and $18 \mathrm{~S}$ rRNA as a control for quantity of RNA. CPT-I and GLUT4 mRNA levels were analysed by RTPCR and normalised to the expression of $18 \mathrm{~S}$ rRNA. Data represent means and their standard errors for 6-10 animals per group and are expressed relative to the mean value of the control group, which was set to 100. Significant differences were tested by Student's $t$ test one. Mean values for the CLA supplemented diet were significantly different from the controls: ${ }^{\star} P<0.05$.

Rodriguez et al. 2002). Thus, the present study refers specifically to the effects of a single CLA isomer, the one particularly used as a main component in commercial preparations for human consumption (trans-10, cis-12-CLA) and not a mixture as was tested in the vast majority of previously reported in vivo studies (Navarro et al. 2006).

Regarding body composition, CLA has been demonstrated to reduce the amount of fat (Pariza, 2004). Among the different species studied, the mouse has been shown to be the most sensitive to CLA, while the effects of CLA on rats has been generally less marked. We have previously shown that hamsters show an intermediate response between mice and rats (Navarro et al. 2003); thus, we considered it interesting to analyse the effects of CLA feeding in this species.

One of the potential mechanisms accounting for a decrease in fat content could be through an increase in thermogenesis, which in small mammals is mediated by the UCP and, particularly, BAT (Palou et al. 1998; Cannon \& Nedergaard, 2004). Nevertheless, the analysis of the effects of CLA on UCP is scarce in the literature and has led to contradictory results. The vast majority of the studies have been performed in mice. One of the most frequently reported effects in this animal model is increased UCP2 expression in WAT (Tsuboyama-Kasaoka et al. 2000; Ealey et al. 2002; Roche et al. 2002; Warren et al. 2003) and BAT (West et al. 2000; Ealey et al. 2002; Roche et al. 2002; Takahashi et al. 2002), although other authors have found no significant changes in WAT (Takahashi et al. 2002). The effects on UCP1 in BAT have also been considered: some authors have found decreased mRNA levels after CLA feeding (Ealey et al. 2002; Takahashi et al. 2002) but others found no significant changes (West et al. 2000). With regard to UCP3, increased expression in skeletal muscle has been reported by Roche et al. (2002) but this UCP remains unchanged in other studies (Ealey et al. 2002; Takahashi et al. 2002). In SpragueDawley rats, no changes in the expression of UCP were observed by using either trans-10, cis-12 or a CLA mixture (Ealey et al. 2002).

The different results published concerning the effects of CLA on UCP expression in BAT can be attributed, at least partially, to the different effects produced by both main isomers of CLA. Most of the in vivo studies have used mixtures containing several CLA isomers, mainly cis-9, trans-11 and trans-10, cis-12 in equal concentration. By using cultured brown adipocytes, we have described opposite effects of both CLA isomers on thermogenic capacity (Rodriguez et al. 2002): trans-10, cis-12 CLA inhibits both UCP1 and UCP2 mRNA expression, while the cis-9, trans-11 isomer increases UCP1 expression.

Our results show a decrease rather than an increase in UCP1 expression in BAT, while UCP2 expression was not detected, and the effects on UCP3 if any were not statistically significant. We also measured UCP expression in subcutaneous and perirenal WAT depots. We found no significant effects on UCP2 expression by the trans-10, cis-12 CLA treatment. Of interest, we found significant UCP1 expression in the perirenal WAT, but not in the subcutaneous depot, and its expression was also significantly reduced by CLA feeding, as in BAT. CLA feeding also reduced UCP3 expression in subcutaneous WAT, without affecting its expression in the perirenal depot. Although we do not have a direct measure of core temperature, these results suggest that CLA effects in hamsters are not mediated through adipose tissue thermogenesis.

The effect of CLA increasing UCP3 mRNA expression in skeletal muscle differed from that described for adipose tissues. Tissue-specific responses in UCP3 regulation have also been reported under other experimental conditions such as triiodothyronine treatment and retinoid treatments, and fasting (Gong et al. 1997; Felipe et al. 2003).

UCP3 has been proposed to be more important as a regulator of fatty acid utilisation than as an uncoupler involved in thermogenesis (Samec et al. 1998). Thus, UCP3 in skeletal muscle seems to be primarily associated with the regulation of lipids as fuel and increased fatty acid oxidation (Wang et al. 2003; Bezaire et al. 2005). Here we show that not only UCP3 but also CPT-I expression were up regulated by the high dose of CLA. We have previously reported increased CPT-I activity in skeletal muscle of hamsters fed either $0.5 \%$ or $1 \%$ trans-10, cis-12 CLA (Zabala et al. 2006). Thus, considering that skeletal muscle plays the largest role in fatty acid oxidation in the body due to its relative whole size, it can be proposed that increased fatty acid oxidation in skeletal muscle is one of the mechanisms that contributes to the decrease in adiposity induced by trans10, cis-12 CLA. On the other hand, although no significant changes were found in skeletal muscle concerning the expression of GLUT4, an important determinant of the muscle capacity for glucose transport activated by insulin (Henriksen et al. 1990), a tendency to lower expression levels (30\% decrease compared with controls) as an effect of CLA treatment may indicate some preferential use of fatty acids instead of glucose as fuel. 
Different results have been published concerning the effect of CLA on muscle GLUT4 expression. Tsuboyama-Kasaoka et al. (2000) found increased GLUT4 expression levels in gastrocnemius muscle of C57BL/6J mice fed CLA, while other authors, Henriksen et al. (2003), in diabetic Zucker rats, and Takahashi et al. (2002), in two different strains of mice, did not find significant effects. We also determined GLUT4 mRNA expression levels in muscle in a reduced group of three animals fed a standard diet, instead of the atherogenic diet, and levels were significantly lower than those of animals fed the atherogenic diet free of CLA (37.8 (SEM 18.0) \%). Thus, it should be mentioned that the effect of CLA on GLUT4 mRNA expression in the muscle would tend to normalise the increased expression caused by feeding the atherogenic diet used in the present experimental design.

UCP3 expression in muscle is stimulated by the elevation of circulating NEFA. However, it is not likely that the up-regulation of UCP3 found in this study is explained by this mechanism because we previously found no changes in the concentration of circulating NEFA in hamsters as an effect of $0.5 \%$ CLA feeding in the same conditions as in this study (Simon et al. 2006). This is in agreement with the concept that regulation of UCP3 expression by fat could be more related to actual increases in the rate of fat oxidation than to high NEFA levels per se. In fact, studies in human subjects under high fat diets showed increased fat oxidation and UCP3 expression in muscle that were not accompanied by increases in circulating NEFA levels (Schrauwen et al. 1997, 2001).

We also determined leptin mRNA expression levels in adipose tissue from different anatomical localisations. We found that, in hamsters, leptin is expressed at higher levels in the subcutaneous than in the perirenal WAT; in the latter, lower leptin expression can be related to significant expression of UCP1, thus indicating differences between both fat depots. In both depots, leptin mRNA expression decreased as an effect of CLA feeding, independently of the dose. This decrease can be related to the decrease in the size of these fat depots. Leptin expression in BAT was not affected by CLA feeding, neither was the size of this depot. A trend to lower circulating leptin levels was also observed after CLA feeding. A decrease in blood leptin levels as an effect of CLA treatment has been previously described in C57BL76J mice (Tsuboyama-Kasaoka et al. 2000; Yamasaki et al. 2000; Rahman et al. 2001). It is known that leptin can enhance insulin-mediated stimulation of glucosal disposal (Kamohara et al. 1997; Cusin et al. 1998). Thus, the decrease in leptin expression as an effect of CLA could be one of the mechanisms that contribute to the development of insulin resistance, as previously suggested (Tsuboyama-Kasaoka et al. 2000).

We have previously described that although trans-10, cis12-CLA feeding in hamsters prevents adiposity, it cannot prevent insulin resistance induced by feeding an atherogenic diet. Since no changes were found either in blood glucose and insulin levels or in the homeostatic model assessment for insulin resistance index with both doses of CLA used (Simon et al. 2006; Zabala et al. 2006), then the potential involvement of the decreased leptin production, as well as the tendency to decreased GLUT4 transporter expression in gastrocnemious muscle, in the maintenance of impaired insulin sensitivity cannot be ruled out. In spite of the effect of CLA on the size of adipose tissue depots, we did not find significant differences between the three experimental groups concerning resistin expression, which in rodents is related to the development of insulin resistance (Kusminski et al. 2005).

In summary, our results do not sustain increased thermogenesis in the adipose tissue, mediated by UCP, as a clear determinant of trans-10, cis-12 CLA body-fat lowering effect. Rather, skeletal muscle UCP3 and CPT-I up-regulation seems to be related to increased fatty acid oxidation and, thus, decreased availability of this lipid species for TAG accumulation.

\section{Acknowledgements}

This work was supported by the Spanish Government (grants G03/028, BFI2003-04 439, and AGL 2004-07 496/ALI to A. P. and BFI2002-0273 to M. P. P.) and the University of the Basque Country (grant GIU03/18 to M. P. P.). The group of Bioquímica, Biología Molecular, Nutrición y Biotecnología (Nutrigenómica) of the UIB is a member of the European Research Network of Excellence NuGO (The European Nutrigenomics Organization, EU Contract: FP6-506360).

\section{References}

Azain MJ, Hausman DB, Sisk MB, Flatt WP \& Jewell DE (2000) Dietary conjugated linoleic acid reduces rat adipose tissue cell size rather than cell number. J Nutr 130, 1548-1554.

Bezaire V, Spriet LL, Campbell S, Sabet N, Gerrits M, Bonen A \& Harper ME (2005) Constitutive UCP3 overexpression at physiological levels increases mouse skeletal muscle capacity for fatty acid transport and oxidation. Faseb J 19, 977-979.

Brodie AE, Manning VA, Ferguson KR, Jewell DE \& Hu CY (1999) Conjugated linoleic acid inhibits differentiation of pre- and postconfluent 3T3-L1 preadipocytes but inhibits cell proliferation only in preconfluent cells. J Nutr 129, 602-606.

Cannon B \& Nedergaard J (2004) Brown adipose tissue: function and physiological significance. Physiol Rev 84, 277-359.

Cusin I, Zakrzewska KE, Boss O, Muzzin P, Giacobino JP, Ricquier D, Jeanrenaud B \& Rohner-Jeanrenaud F (1998) Chronic central leptin infusion enhances insulin-stimulated glucose metabolism and favors the expression of uncoupling proteins. Diabetes $\mathbf{4 7}$, 1014-1019.

Cherian G, Holsonbake TB, Goeger MP \& Bildfell R (2002) Dietary CLA alters yolk and tissue FA composition and hepatic histopathology of laying hens. Lipids 37, 751-757.

Choi JS, Jung MH, Park HS \& Song J (2004) Effect of conjugated linoleic acid isomers on insulin resistance and mRNA levels of genes regulating energy metabolism in high-fat-fed rats. Nutrition 20, 1008-1017.

Ealey KN, El-Sohemy A \& Archer MC (2002) Effects of dietary conjugated linoleic acid on the expression of uncoupling proteins in mice and rats. Lipids 37, 853-861.

Evans M, Brown J \& McIntosh M (2002a) Isomer-specific effects of conjugated linoleic acid (CLA) on adiposity and lipid metabolism. J Nutr Biochem 13, 508.

Evans M, Geigerman C, Cook J, Curtis L, Kuebler B \& McIntosh M (2000) Conjugated linoleic acid suppresses triglyceride accumulation and induces apoptosis in 3T3-L1 preadipocytes. Lipids 35, 899-910.

Evans M, Lin X, Odle J \& McIntosh M (2002b) Trans-10, cis-12 conjugated linoleic acid increases fatty acid oxidation in 3T3-L1 preadipocytes. J Nutr 132, 450-455. 
Felipe F, Bonet ML, Ribot J \& Palou A (2003) Up-regulation of muscle uncoupling protein 3 gene expression in mice following high fat diet, dietary vitamin A supplementation and acute retinoic acid-treatment. Int J Obes Relat Metab Disord 27, 60-69.

Gaullier JM, Berven G, Blankson H \& Gudmundsen O (2002) Clinical trial results support a preference for using CLA preparations enriched with two isomers rather than four isomers in human studies. Lipids 37, 1019-1025.

Gavino VC, Gavino G, Leblanc MJ \& Tuchweber B (2000) An isomeric mixture of conjugated linoleic acids but not pure cis-9, trans-11-octadecadienoic acid affects body weight gain and plasma lipids in hamsters. J Nutr 130, 27-29.

Gong DW, He Y, Karas M \& Reitman M (1997) Uncoupling protein-3 is a mediator of thermogenesis regulated by thyroid hormone, beta3-adrenergic agonists, and leptin. J Biol Chem 272, 24129-24132.

Henriksen EJ, Bourey RE, Rodnick KJ, Koranyi L, Permutt MA \& Holloszy JO (1990) Glucose transporter protein content and glucose transport capacity in rat skeletal muscles. Am J Physiol 259, E593-E598.

Henriksen EJ, Teachey MK, Taylor ZC, Jacob S, Ptock A, Kramer K \& Hasselwander O (2003) Isomer-specific actions of conjugated linoleic acid on muscle glucose transport in the obese Zucker rat. Am J Physiol Endocrinol Metab 285, E98-E105.

Kamohara S, Burcelin R, Halaas JL, Friedman JM \& Charron MJ (1997) Acute stimulation of glucose metabolism in mice by leptin treatment. Nature 389, 374-377.

Kamphuis MM, Lejeune MP, Saris WH \& Westerterp-Plantenga MS (2003) Effect of conjugated linoleic acid supplementation after weight loss on appetite and food intake in overweight subjects. Eur J Clin Nutr 57, 1268-1274.

Kritchevsky D, Tepper SA, Wright S, Tso P \& Czarnecki SK (2000) Influence of conjugated linoleic acid (CLA) on establishment and progression of atherosclerosis in rabbits. J Am Coll Nutr 19, 472S-477S.

Kusminski CM, McTernan PG \& Kumar S (2005) Role of resistin in obesity, insulin resistance and Type II diabetes. Clin Sci (Lond) 109, 243-256.

Macarulla MT, Fernandez-Quintela A, Zabala A, Navarro V, Echevarria E, Churruca I, Rodriguez VM \& Portillo MP (2005) Effects of conjugated linoleic acid on liver composition and fatty acid oxidation are isomer-dependent in hamster. Nutrition 21, $512-519$.

Martin JC \& Valeille K (2002) Conjugated linoleic acids: all the same or to everyone its own function? Reprod Nutr Dev 42, 525-536.

Navarro V, Zabala A, Macarulla MT, Fernandez-Quintela A, Rodriguez VM, Simon E \& Portillo MP (2003) Effects of conjugated linoleic acid on body fat accumulation and serum lipids in hamsters fed an atherogenic diet. J Physiol Biochem 59, 193-199.

Navarro V, Zabala A, Macarulla MT, Fernandez-Quintela A, Rodriguez VM, Simon E \& Portillo MP (2006) The body fat-lowering effect of conjugated linoleic acid: comparison between animal and human studies. J Physiol Biochem 62, $137-148$.

Oliver P, Pico C, Martinez N, Bonet ML \& Palou A (2000) In vivo effects of CGP-12177 on the expression of leptin and uncoupling protein genes in mouse brown and white adipose tissues. Int J Obes Relat Metab Disord 24, 423-428.

Ostrowska E, Suster D, Muralitharan M, Cross RF, Leury BJ, Bauman DE \& Dunshea FR (2003) Conjugated linoleic acid decreases fat accretion in pigs: evaluation by dual-energy X-ray absorptiometry. Br J Nutr 89, 219-229.

Palou A, Pico C, Bonet ML \& Oliver P (1998) The uncoupling protein, thermogenin. Int J Biochem Cell Biol 30, 7-11.

Pariza MW (2004) Perspective on the safety and effectiveness of conjugated linoleic acid. Am J Clin Nutr 79, 1132S-1136S.
Pariza MW, Ashoor SH, Chu FS \& Lund DB (1979) Effects of temperature and time on mutagen formation in pan-fried hamburger. Cancer Lett 7, 63-69.

Park Y, Albright KJ, Liu W, Storkson JM, Cook ME \& Pariza MW (1997) Effect of conjugated linoleic acid on body composition in mice. Lipids 32, 853-858.

Rahman SM, Wang Y, Yotsumoto H, Cha J, Han S, Inoue S \& Yanagita T (2001) Effects of conjugated linoleic acid on serum leptin concentration, body-fat accumulation, and beta-oxidation of fatty acid in OLETF rats. Nutrition 17, 385-390.

Reeves PG, Nielsen FH \& Fahey GC Jr (1993) AIN-93 purified diets for laboratory rodents: final report of the American Institute of Nutrition ad hoc writing committee on the reformulation of the AIN-76 rodent diet. J Nutr 123, 1939-1951.

Ribot J, Felipe F, Bonet ML \& Palou A (2001) Changes of adiposity in response to vitamin A status correlate with changes of PPAR gamma 2 expression. Obes Res 9, 500-509.

Roche HM, Noone E, Sewter C, McBennett S, Savage D, Gibney MJ, O'Rahilly S \& Vidal-Puig AJ (2002) Isomer-dependent metabolic effects of conjugated linoleic acid: insights from molecular markers sterol regulatory element-binding protein-1c and LXRalpha. Diabetes 51, 2037-2044.

Rodriguez E, Ribot J \& Palou A (2002) Trans-10, cis-12, but not cis-9, trans-11 CLA isomer, inhibits brown adipocyte thermogenic capacity. Am J Physiol Regul Integr Comp Physiol 282, R1789-R1797.

Ryder JW, Portocarrero CP, Song XM, et al. (2001) Isomer-specific antidiabetic properties of conjugated linoleic acid. Improved glucose tolerance, skeletal muscle insulin action, and UCP-2 gene expression. Diabetes 50, 1149-1157.

Samec S, Seydoux J \& Dulloo AG (1998) Role of UCP homologues in skeletal muscles and brown adipose tissue: mediators of thermogenesis or regulators of lipids as fuel substrate? Faseb $J \mathbf{1 2}$, $715-724$

Schrauwen P, Hoppeler H, Billeter R, Bakker AH \& Pendergast DR (2001) Fiber type dependent upregulation of human skeletal muscle UCP2 and UCP3 mRNA expression by high-fat diet. Int J Obes Relat Metab Disord 25, 449-456.

Schrauwen P, van Marken Lichtenbelt WD, Saris WH \& Westerterp KR (1997) Changes in fat oxidation in response to a high-fat diet. Am J Clin Nutr 66, 276-282.

Simon E, Macarulla MT, Churruca I, Fernandez-Quintela A \& Portillo MP (2006) Trans-10, cis-12 conjugated linoleic acid prevents adiposity but not insulin resistance induced by an atherogenic diet in hamsters. J Nutr Biochem 17, 126-131.

Simon E, Macarulla MT, Fernandez-Quintela A, Rodriguez VM \& Portillo MP (2005) Body fat-lowering effect of conjugated linoleic acid is not due to increased lipolysis. $J$ Physiol Biochem 61, 363-369.

Takahashi Y, Kushiro M, Shinohara K \& Ide T (2002) Dietary conjugated linoleic acid reduces body fat mass and affects gene expression of proteins regulating energy metabolism in mice. Comp Biochem Physiol B Biochem Mol Biol 133, 395-404.

Terpstra AH (2004) Effect of conjugated linoleic acid on body composition and plasma lipids in humans: an overview of the literature. Am J Clin Nutr 79, 352-361.

Tsuboyama-Kasaoka N, Takahashi M, Tanemura K, Kim HJ, Tange T, Okuyama H, Kasai M, Ikemoto S \& Ezaki O (2000) Conjugated linoleic acid supplementation reduces adipose tissue by apoptosis and develops lipodystrophy in mice. Diabetes 49, 1534-1542.

Wang S, Subramaniam A, Cawthorne MA \& Clapham JC (2003) Increased fatty acid oxidation in transgenic mice overexpressing UCP3 in skeletal muscle. Diabetes Obes Metab 5, 295-301.

Warren JM, Simon VA, Bartolini G, Erickson KL, Mackey BE \& Kelley DS (2003) Trans-10, cis-12 CLA increases liver and decreases adipose tissue lipids in mice: possible roles of specific lipid metabolism genes. Lipids 38, 497-504. 
West DB, Blohm FY, Truett AA \& DeLany JP (2000) Conjugated linoleic acid persistently increases total energy expenditure in $\mathrm{AKR} / \mathrm{J}$ mice without increasing uncoupling protein gene expression. J Nutr 130, 2471-2477.

Yamasaki M, Mansho K, Ogino Y, Kasai M, Tachibana H \& Yamada K (2000) Acute reduction of serum leptin level by dietary conjugated linoleic acid in Sprague-Dawley rats. J Nutr Biochem 11, 467-471.

Zabala A, Fernandez-Quintela A, Macarulla MT, Simon E, Rodriguez VM, Navarro V \& Portillo MP (2006) Effects of conjugated linoleic acid on skeletal muscle triacylglycerol metabolism in hamsters. Nutrition 22, 528-533. 